\title{
Choice of Marketing Mix and Forecast on the Net Margin of K-Packs for SMARTFOOD
}

\author{
Yiwen Zhang ${ }^{1, *}{ }^{* \dagger}$ Lehan Zhang ${ }^{2, \dagger}$ \\ ${ }^{1}$ Department of Applied Science, Beijing, 100051, China \\ ${ }^{2}$ International Academy, Quanzhou, 362021, China \\ *Yiwen Zhang. Email: zhangyiwen0512@emails.bjut.edu.cn \\ Lehan Zhang. Email: Astrid_Lehan@stu.hqu.edu.cn \\ These authors contributed equally.
}

\begin{abstract}
Sales can be affected by many factors including both external and internal ones and the optimal marketing choice can maximum sales to a certain degree. In this paper, two business analysis models, PEST and SWOT, and a multiple linear regression model are applied. It is found that K-Pack has many advantages and opportunities as well as a promising future for both political and social perspectives such as the increasing trend for healthy snacks of the public if SMARTFOOD company can assess its disadvantages and risks such as the emergence of substitutes. Also, it can be concluded that the introduction time length, advertising method, store volume, price and the interaction between price and store volume have positive effects on the sales significantly. Considering both business analysis models and the regression model, the marketing mix is to set the K-Packs at the bakery food section and use the \$3.5 million advertising plan and the price of 70 cents per packages and the predicted national net margin for the first year is $\$ 7$ million. The logic and analysis of this paper are comprehensive and practical. Also, the methods and models applied in this paper can be used for references or choices of thinking for similar cases or circumstances of other business companies. Moreover, the weaknesses of the models can also be useful for other researchers.
\end{abstract}

Keywords: PEST, SWOT, MLR, Marketing mix

\section{INTRODUCTION}

For any business, sales can be affected by various factors which can be categorized into two kinds----the external forces and the internal influence. As for the external forces, lots of factors, such as political, economic and environmental factors, can be influential. Different buyers' demands, including the number of consumers and their composition, level of purchase ability and motivation of purchase, can affect sales differently. The competition of the market, such as introduction amount of product, updating of the old and the new and competitions among similar business, can also be crucial factors. When there is a promising economic environment, demands will increase and therefore the sales will go up as well. As for the business itself, economic competence, quality of its employees and its market share can all have some different degrees of influence. Also, lots of indirect influence of sales, such as climate, region, custom or even religion, cannot be underestimated. As for the internal factors, different aspects of the product itself can have a direct influence on sales. For instance, for all kinds of products, quality and price are always the influence factors of all time. Also, if it is a food product, the flavor and novelty matter. If it is personal adornment, then its style, setting of sizes and colors also matters. If it is practical products, its function and appearance are also important.

In this case, a newly introduced food product, KPack, has just entered the market. To predict sales and profit and to maximum annual sales, three levels of price, two ways of advertising and two locations of the setting are to be considered among different sizes of stores within or among cities. The goal is to decide the final marketing mix using the sample data.

The SWOT and PEST model are usually applied in business cases and analyses. Swangjang and Kornpiphat [5] utilized SWOT and DPSIR to analyze data statistically based on questionnaire interviews with three target groups and they assessed the ecotourism carrying 
capacity of the area. Rizzo and Kim [6] also used SWOT analysis for the field of VR rehabilitation and therapy and they found that it can be usefully applied to assess and guide any organized human endeavour designed to accomplish a mission. Yan et al. [7] used SWOT-PEST analysis and found that the implementation of strengthening cooperation, increasing financial input, improving staff's qualities, plus using the new technology can promote cultural tourism development in Guanzhong-Tianshui economic zone. Doherty et al. [8] utilized PEST analysis upon the Australasian higher education environment and they found significant challenges for professional societies and offered some strategic insights for similar regional societies and their executive teams. Alava et al. [9] also used this method based on neutrosophic cognitive maps static analysis and ranked relevant factors based on interrelation and incorporating indeterminacy.

There is lots of similar research using the multiple linear regression model to predict all sorts of variables. Jia et al. [1] utilized multiple linear regression algorithms and predicted the aging process and the webserver parameters. The result shows that this algorithm can be used to predict the aging process in the allowable error range. Ul-Saufie et. Al. [2] also used multiple linear regression models to predict near future PM10 concentration levels in Seberang Perai, Malaysia and they found that this model is feasible. Hai-Hong et al. [3] used the same method and effectively predicted the yield rural household solid waste. Shan et.al. [4] presented a spatial-temporal method based on multiple linear regression model and calculated the traffic speed of the segments without certain data.

There are various influential factors of sales shown in other research. Yu et al. [10] utilized the investigation method of a questionnaire and found that gender, cognitive levels convenience of purchase and preference for certain brands are contributing to the sales of fruits in Taiwan, China significantly. Dodd and Gustafson [11] used the regression method and concluded that several wine brands, environment and service attributes have a significant impact upon consumer attitudes and purchases. Also, product and purchase involvement were also found to impact purchase behavior. Noh et al. [12] applied the spatial error model, SEM for analyzing spatial autocorrelation and they found that the floating population, the number of nearby workers and the area of aggregation unit effect positively on foodservice sales.

In this paper, we consider business analysis and regression models to analyse the SMARTFOOD. Firstly, in the business model, we used PEST and SWOT. PEST looks at the external factors. The U.S. government supports the emergence of low-quality food, which lies a positive impact on k-pack. Also, K-Pack needs plans for everything from its pricing and marketing methods to its market strategy based on the overall environment, and the
SMARTFOOD company must assess the risks. What's more, SMARTFOOD should enter the market and apply for a patent as soon as possible to monopoly the market and avoid duplication of other companies. SWOT analyses K-Pack itself from strengths and opportunities as well as weaknesses and threats. As for the strengths, $\mathrm{K}$-Pack is healthy and has no strong competitors in the next two years. Also, it has fine cost control and SMARTFOOD has sufficient preparation about its entering the market. As for the weaknesses, K-Pack has no experience to draw on and its production technology may not be mature enough. Also, like other snacks, it has a possible short life cycle and food safety issue. The opportunities include the support of the government, the global trend towards healthy food. And if SMARTFOOD can solve the issue of short life cycle of the product, it will be strongly competitive. The threats include fierce competition and oligarchy of a similar product and the increasingly uncertain market. The regression model focuses on data statistically. In this case, the dependent variable is the sales and the significant independent variables are month, advertising method, store volume, price and the interaction between the latter two. They all have a positive effect and advertising method has the greatest effect while the interaction between price and store volume has the least effect. Using the regression model, the net margin can be predicted and therefore the best choice of marketing mix can be provided. The logic and analysis of this paper are comprehensive and practical. The methods and models can also be used for references or choices of thinking for similar cases or circumstances of other business companies. Moreover, the weaknesses of the models can be useful for other researchers and if they can conquer these weaknesses, the model will suit the case better and the predicted value more accurately.

The remainder of the paper is organized as follows: Section 2 describes a comprehensive background of the whole case; section 3 performs some business analysis including two relevant models, PEST and SWOT; section 4 conducts the final model used in this case and analyzes the tests results; section 5 calculates the net margin for the first year and introduces the final marketing mix and suggestions using the 4Ps method.

\section{BACKGROUND}

Product Development at SMARTFOOD is considering adding a new low-carbohydrate food product to their snack/diet food product line. The product is tentatively labeled K-Pack and is packaged to look like a typical candy bar.

We believe the product will have very little direct competition in the diet-snack food category in two years if the company can enter the market soon. However, we less certain about the market conditions after two years. 
The result of a small pre-test market study was very encouraging. The initial estimate of annual sales is 750,000 cases of K-Pack ( 24 packages in a case) using a mix of 50 cents per package and 3 million dollars in advertising per year.

Also, we planned to conduct a four-month test market study at 24 grocery stores in four different cities (6 stores in each city). And we believed the above objectives could be achieved using a "controlled" introduction of K-Pack into the four cities. Marketing mix variables were to be varied across grocery stores in each city. Sales of K-Pack were measured using store audits from a panel of stores in each city.

Marketing mix variables were: price, advertising, and location of K-Pack within each store. Specifically, three prices (50 cents, 60 cents, 70 cents), two levels of advertising (a simulation of a $\$ 3$ million introduction plan and a $\$ 3.5$ million plan), and two store locations (L1: K-Pack in the bakery section versus L2: K-Pack in the breakfast food section). Prices and location were to be varied across stores within a city while advertising was varied across cities. Advertising was in the form of spot TV ads. Advertisement levels were selected that would simulate on a local basis the impact of national ads at the level of \$3 million and \$3.5 million.

All the following studies of this paper would base on the information above.

\section{BUSINESS ANAYSIS}

In this section, we conduct PEST analysis to investigate the environmental condition faced by SMARTFOOD. Then, we utilized SWOT analysis to identify the corporate's competition situation in the market. This would help investors to know this company clearly.

\subsection{PEST Analysis}

\subsubsection{Political Factors}

Recently, on December 29, 2020, the U.S. Department of Agriculture (USDA) and the Department of Health and Human Services (HHS) released the "Dietary Guidelines for Americans (2020-2025)", which provide advice on "what to eat and drink to meet nutritional needs, promote health, and reduce the risk of chronic disease." The new guidelines, which cover all categories of people throughout their life, set out four health guidelines for healthy people and those at risk of disease, including encouraging residents to make appropriate food and drink choices and to maintain a healthy diet throughout their lives.

It can be seen that all the intervention and attention of the U.S. government over the years of food and health, which can be assumed that the emergence of the lowquality food will be a major support for the development of the government, which will have a favorable positive impact on many aspects of the k-pack.

\subsubsection{Economic Factors}

Recently, the president of U.S proposed the postpandemic recovery plan for the United States and reduce market uncertainty. However, the scale of the second bailout stimulus plan is not large, the new administration will not only rely on the Federal Reserve's extremely loose monetary policy to support the economic recovery, but also there will be a new bailout stimulus plan. This implies a strong rebound in the first half of 2021, but a slow recovery for the next few years due to the pandemic and ethnic polarization. Combined with fiscal stimulus and easy monetary policy, it will strengthen the financialization of the US economy.

Therefore, under such seemingly unsound macroeconomic conditions, K-Pack is needed to make plans for everything from its pricing and marketing methods to its market strategy based on the overall environment, and the SMARTFOOD company must do a good job at risk assessment and control for K-Pack and gradually penetrate the market.

\subsubsection{Social Factors}

Not just in the United States, The Food and Agriculture Organization of the United Nations (FAO) says overweight and obesity are now a global "epidemic", spreading in both developed and developing countries. With the change of people's living standards and dietary structure, the proportion of overweight and obese population is constantly increasing and gradually developing to the younger age. At present, overweight and obesity pose a more serious threat to human body and has become a global problem that cannot be ignored.

When the world pays more and more attention to the problem of a healthy diet, it will lay a good foundation for the globalization of K-pack market and make K-pack more and more diversified in People's Daily life.

Foundation for the globalization of K-pack market and make K-pack more and more diversified in People's Daily life.

In addition, especially for Asian people, the aesthetic concept of thinness is also a good entry point for K-pack as low-carbohydrate food in the Asian market.

\subsubsection{Technological Factors}

The investment in research and development is of great significance to the development of the whole industry, including the food industry. 
In fact, even in high-tech developed countries such as the United States, the decline of $R \& D$ investment will lead to the decline of the development speed of related industries. There is a good proportional relationship between the intensity of R\&D investment and the sales growth of the industry. The slow growth of the food industry in the United States is related to its low R\&D investment.

It is conceivable that in such a rapidly developing environment, if the SMARTFOOD company does not enter the market as soon as possible, they may lose the chance to monopoly or capture the market. Also, many technological competitors of K-Pack are able to duplicate its ingredient method if SMARTFOOD cannot apply for a patent rapidly.

\subsection{SWOT Analysis}

In this part, we used SWOT analysis to introduce the SMARTFOOD's competitiveness ability in the food industry. We consider its strength, weakness, opportunities and threat, respectively.

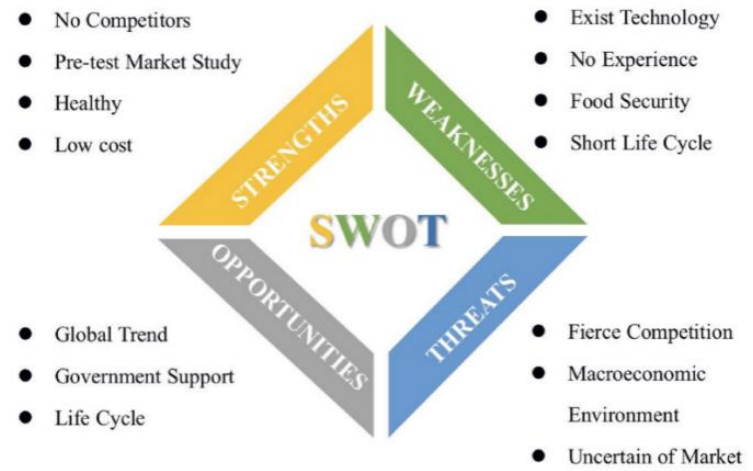

Figure 1. SWOT Analysis

\subsubsection{Strengths}

Firstly, in terms of the nature of K-pack product itself, although it is a snack, it belongs to low-carbohydrate food. Therefore, it is Healthy compared with ordinary desserts. This makes adults who want to keep fit or parents with children choose $\mathrm{K}$-pack because it is more Healthy;

Secondly, as mentioned above, there will be no strong competitors in the next two years, which is the second advantage of K-Pack. It has a stable space for development, so that it can do a good job of this brand steadily and steadily without worrying too much about product differentiation and other issues.

The third advantage is cost. According to the data provided in the case, the Cost of Manufacturing is 9.7 Cents per package. Cost control is very important for any product, which is an important means to enhance its competitiveness. It can help SMARTFOOD Company quickly open the market of low-carbohydrate food.
The last one is sufficient preparation: the Pre - test Market Study the results of the ideal and through regression analysis shows that the result is reliable (part of the article will elaborate regression analysis modelling after), and the benefits of a trial is obvious: get information from the Market tests for the future sales forecast accuracy is relatively high; can test the feasibility of different marketing plans for new product commercialization; From the perspective of consumers feel new product defects, etc.

\subsubsection{Weaknesses}

Because K-pack belongs to new products entering new markets, so there is no other experience to draw on, which means that we can only use trial and error, which greatly improves the risk coefficient; Besides, existing technology of low-carbohydrate food is not mature enough. Compared with ordinary desserts, can the production technology of K-Pack now achieve a low calorie health status without losing the pleasure and enjoyment that desserts can bring to people? Moreover, Short Life Cycle -- Most of the snack products have Short Life cycles. Although K-pack is low food, it is also associated with a snack. Therefore, Short Life cycles are a difficulty that still needs further research: how to break through this Life Cycle and turn K-pack into a group with a long Life? Finally, there is the issue of food safety, which is related to technology and is fundamental to the food production industry itself.

\subsubsection{Opportunities}

As mentioned above, a healthy diet is a Global trend at present. Looking at the extremely high growth rate of the obese population in the US, it can be predicted that the government will definitely give strong support to the development of low-carbohydrate food, which is a very strong support force. As for Life cycles, why are they both Weakness and Opportunity? Reality experience tells us that Most of the snack products have Short Life cycles. However, if SMARTFOOD Company can break through this bottleneck, K-Pack will be highly competitive and stand out among many ordinary and short-lived desserts.

\subsubsection{Threats}

Although this is a model for new products to enter new markets, according to the PEST analysis, the American food industry has fierce competition and oligarchy. If SMARTFOOD Company wants to develop bigger and deeper market opportunities and gain a foothold in the whole food industry, it may not be easy.

Secondly, since the overall economy of the United States is not booming and the economic environment is not so good, the Market is more uncertain than a few years ago. Therefore, Macroeconomic Environment is a threatening point, and the SMARTFOOD Company still 
needs to do a good job in the preliminary work of risk assessment and internal control and management.

\section{REGRESSION ANALYSIS}

In this session, after processing the sample, multiple linear regression is applied to model the relationship between sales and other independent variables. Then the results are analysed in two aspects, that is, the descriptive statistical analysis and the parameter estimation analysis. Finally, using the final prediction model, the net margin is calculated in two ways. After comparing both sales and profit, the final marketing mix is using the $\$ 2.5$ million advertising plan and 70 cents for each package. The final predicted net margin is $\$ 7$ million.

\subsection{Model}

In this case, a multiple linear regression model is applied to investigate the relationships among sales and other independent variables: Price50, Price60, Price50_Volume, Price60_Volume, Advertising, Location, Store Volume and Month and then to further investigate the impact of these variables on sales.

\subsubsection{Multiple Linear Regression \& Ordinary Least Squares}

Multiple regression analysis (MR) is a highly flexible system for examining the relationship of a collection of independent variables (or predictors) to a single dependent variable (or criterion). The relationships are modelled using linear predictor functions whose unknown model parameters are estimated from the data. The multiple linear regression model has the form:

$$
\begin{aligned}
& y_{i}=\beta_{0}+\beta_{1} x_{i 1}+\cdots+\beta_{j} x_{i j}+\cdots+\beta_{p} x_{i p}+\varepsilon_{i}, \\
& i=1,2, \ldots, n, j=1,2, \ldots, p
\end{aligned}
$$

is the $\mathrm{i}^{\text {th }}$ observation; is the regression intercept; is the $\mathrm{j}^{\text {th }}$ predictor's regression slope; is the $\mathrm{j}^{\text {th }}$ predictor for the $\mathrm{i}^{\text {th }}$ observation; follows a normal distribution with mean as 0 and variance as and it is a Gaussian error term.

Ordinary least squares(ols) is the basic idea of multiple linear regression. It is a kind of mathematical tool that is widely applied among data processing of various fields.

The least squares function is given by:

$$
L=\sum_{i=1}^{n} \varepsilon_{i}^{2}=\sum_{i=1}^{n}\left(y_{i}-\beta_{0}-\sum_{j=1}^{P} \beta_{j} x_{i j}\right)^{2}
$$

The least squares estimates must satisfy:

$$
\left.\frac{\partial L}{\partial \beta_{0}}\right|_{\widehat{\beta}_{0}, \widehat{\beta}_{1}, \ldots, \widehat{\beta}_{p}}=-2 \sum_{i=1}^{n}\left(y_{i}-\hat{\beta}_{0}-\sum_{j=1}^{P} \hat{\beta}_{j} x_{i j}\right)^{2}
$$

$$
\begin{gathered}
\left.\frac{\partial L}{\partial \beta_{j}}\right|_{\widehat{\beta}_{0}, \widehat{\beta}_{1}, \ldots, \widehat{\beta}_{p}}=-2 \sum_{i=1}^{n}\left(y_{i}-\hat{\beta}_{0}-\sum_{j=1}^{P} \hat{\beta}_{j} x_{i j}\right)^{2} \\
j=0,1,2, \ldots, p ;
\end{gathered}
$$

The equations for ordinary least squares are:

$\sum_{i=1}^{n} y_{i}=n \hat{\beta}_{0}+\hat{\beta}_{1} \sum_{i=1}^{n} x_{i 1}+\hat{\beta}_{2} \sum_{i=1}^{n} x_{i 2}+\cdots+$

$\hat{\beta}_{p} \sum_{i=1}^{n} x_{i p}$;

$\sum_{i=1}^{n} x_{i 1} y_{i}=\hat{\beta}_{0} \sum_{i=1}^{n} x_{i 1}+\hat{\beta}_{1} \sum_{i=1}^{n} x_{i 1}^{2}+$

$\hat{\beta}_{2} \sum_{i=1}^{n} x_{i 1} x_{i 2}+\cdots+\hat{\beta}_{p} \sum_{i=1}^{n} x_{i 1} x_{i p}$;

$\sum_{i=1}^{n} x_{i k} y_{i}=\hat{\beta}_{0} \sum_{i=1}^{n} x_{i k}+\hat{\beta}_{1} \sum_{i=1}^{n} x_{i k} x_{i 1}+$

$\hat{\beta}_{2} \sum_{i=1}^{n} x_{i k} x_{i 2}+\cdots+\hat{\beta}_{p} \sum_{i=1}^{n} x_{i k} x_{i p}$;

The solution to the equations above is the least squares estimators of the regression coefficients.

\subsubsection{Variables Screening}

Because of the independent variables given and their limitations, the data needs to be revised to better fit the regression model. Meanwhile, variables should be screened. Some variables are added into the model while some are extracted out of the model.

Firstly, a boxplot is drawn and shown in Fig. 2. Through this and consideration of reality, whether City Index should be kept in this model can be decided. It shows an increasing trend between sales and the city index. But in reality, K-Packs will not be sold only in 4 cities. So in the final profit prediction, the exact value of city index is unknown. Because of this limitation, it is extracted from the model.

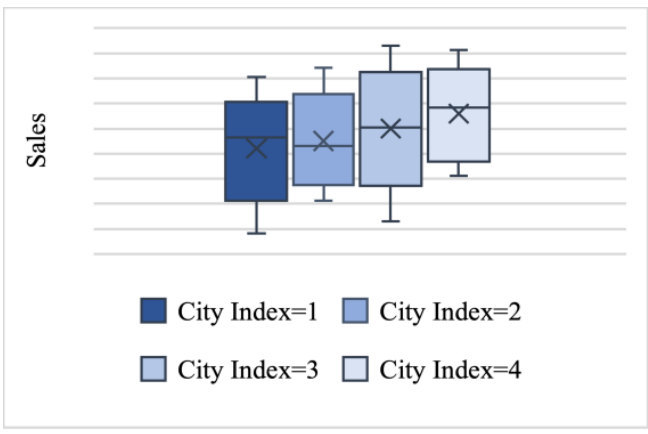

Figure 2. Boxplot of Sales and City Index

Secondly, a new independent variable is added into the model named as Month because the sales are from four different months, indicating the relationship between sales and month is unknown and needs to be investigated.

Thirdly, Price is treated as dummy variables. There are three levels of price, 50 cents, 60 cents and 70 cents, so two dummy variables are added as new independent variables, named as Price50 and Price60.

Finally, to investigate the interaction of price and store volume, two more independent variables are added 
into the model using the product of price and store volume named as Price50_Volume and Price60_Volume.

\subsubsection{Final Model}

Table 1 shows that the dependent variable is the sales(MS) and the independent variables are Price50(P50), Price60(P60), Price50_Volume(PV50), Price60_Volume(PV60), Advertising(Ad), Location(L), Store Volume(Vol) and Month(M).

Table 1. Notations

\begin{tabular}{ll}
\hline Variables (Abbreviation) & Description \\
\hline Sales (MS) & Monthly sales (Cases) \\
Price50 (P50) & 1 if 50 cents, 0 otherwise \\
Price60 (P60) & 1 if 60 cents, 0 otherwise \\
Price50_Volume (PV50) & $\begin{array}{l}\text { product of price50 and } \\
\text { store volume }\end{array}$ \\
Price60_Volume (PV60) & $\begin{array}{l}\text { product of price } 60 \text { and } \\
\text { store volume }\end{array}$ \\
Advertising (Ad) & $\begin{array}{l}1 \text { if } \$ 3.5 \text { million, } 0 \\
\text { otherwise }\end{array}$ \\
Location (L) & $\begin{array}{l}1 \text { if bakery section, } 0 \\
\text { otherwise }\end{array}$ \\
Store Volume (Vol) & (\$00,000) \\
Month (M) & $1,2,3$, or 4
\end{tabular}

To conduct the multiple linear regression, enter all the independent variables into the model. The final equation should be as follows:

$M S=\beta_{0}+\beta_{1} \cdot P 50+\beta_{2} \cdot P 60+\beta_{3} \cdot P V 50+\beta_{4}$.

$P V 60+\beta_{5} \cdot A d+\beta_{6} \cdot L+\beta_{7} \cdot V o l+\beta_{8} \cdot M$

\subsection{Results}

In this session, the continuous variables are analyzed using the descriptive statistical analysis. And then, based on formula (8), multiple linear regression is applied to all the independent variables. By checking various indexes, such as adjusted $\mathrm{R}$ square, p-values, student deleted residual and so on, the final model can be established.

\subsubsection{Descriptive Statistical Analysis}

The descriptive statistical analysis is shown in Table 2. The sales range from 41 to 415 and the standard deviation is relatively high, indicating the sales fluctuated dramatically and therefore it is better to introduce all the values into the model, instead of introducing the mean value of the same month. Store volume ranges from 40 to 59 with a mean of 48.5417 and a standard deviation of 5.52109. The Table 4 shows the number of stores within different range of store volume in this nation. Considering both descriptive statistics of store volume in Table 2 and statistics in Table 3, it can be concluded that there is few large-scale stores whose store volume is between $60-70$ in this nation.

Table 2. Descriptive Statistics

\begin{tabular}{lllll}
\hline $\begin{array}{l}\text { Variable } \\
\mathrm{s}\end{array}$ & $\begin{array}{l}\text { Minimu } \\
\mathrm{m}\end{array}$ & $\begin{array}{l}\text { Maxim } \\
\text { um }\end{array}$ & Mean & $\begin{array}{l}\text { Std. } \\
\text { Deviatio } \\
\mathrm{n}\end{array}$ \\
\hline Sales & 41 & 415 & 243.6667 & 77.77669 \\
$\begin{array}{l}\text { Store } \\
\text { Volume }\end{array}$ & 40 & 59 & 48.5417 & 5.52109 \\
\hline
\end{tabular}

Table 3 shows the national frequency distribution of stores. Nearly half of the stores $(46.5 \%)$ are within the store volume of $\$ 5,000,000-\$ 6,000,000$, which means there are not a lot of large-scale and small-scale stores. Also, the proportion of smallest-scale stores $(9.3 \%)$ whose range of store volume is $\$ 4,000,000-\$ 4,500,000$ is similar with that of the largest-scale stores(11.6\%). Fig. 3 shows the plot of frequency distribution using the median of each range of store volume and it can be assumed that it follows an approximately normal distribution.

Table 3. Frequency Distribution of Stores

\begin{tabular}{ll}
\hline Store Volume(\$00,000) & Frequency(No. of stores) \\
\hline $40-45$ & 20 \\
$45-50$ & 35 \\
$50-55$ & 50 \\
$55-60$ & 50 \\
$60-65$ & 35 \\
$65-70$ & 25 \\
\hline Total & 215 \\
\hline
\end{tabular}

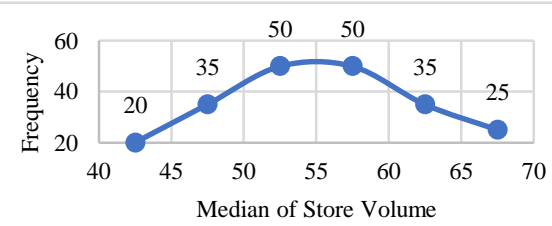

Figure 3. Scatterplot of Frequency and Median of Store Volume

\subsubsection{Parameter Analysis}

Table 4 summarizes the parameter estimates and shows the test results of the final model. Among the eight independent variables, there are five significant variables, M, Ad, PV50, Vol and P60, and they all have a positive effect on the sales. Among them, Ad has the greatest effect and PV50 has the least effect. Also, P60 is the least significant variable while others are all very significant. To be more specific, when one unit of advertising is added into the equation, the sales will increase by almost 50 cases. When one unit of Store Volume is added into the equation, the sales will increase 
by 4.138 cases. Also, nearly 39 more cases of K-Packs will be promoted each month.

Table 4. Parameter Estimation Results of the Model

\begin{tabular}{ll}
\hline Variables & $\beta$ \\
\hline$\beta_{0}$ & $-110.398^{*}$ \\
& $(-1.898)$ \\
P50 & -1.359 \\
& $(-1.492)$ \\
& $27.107^{*}$ \\
P60 & $(1.950)$ \\
& $1.286^{* * *}$ \\
PV50 & $(4.293)$ \\
& -0.846 \\
PV60 & $(-1.209)$ \\
& $49.525 * * *$ \\
Ad & $(4.507)$ \\
& 0.039 \\
L & $(0.539)$ \\
& $4.138^{* * *}$ \\
Vol & $(3.870)$ \\
& $38.835^{* * *}$ \\
M & $(8.050)$ \\
& 0.519 \\
\hline Adjusted R Square & \\
\hline Note: Statistics in parentheses. ${ }^{*} \mathrm{p}<0.1, * * \mathrm{p}<0.05, * * * \mathrm{p}<0.01$ \\
& \\
&
\end{tabular}

\section{DISCUSSION AND RECOMMENDATION}

Firstly, the net margin is calculated in two ways. In basic computation, the profit is calculated without the help of the regression model. As for the advanced computation, the profit is predicted using the regression model. Secondly, some recommendations and suggestions are given on the basis of the 4Ps method, which means analysing the marketing mix from four aspects: price, place, product and promotion strategy and giving support for the results of the regression model.

\subsection{Profit Computations}

One of the main goals in this case is to calculate the net margin of the first year (national sales). There are 24 packages in each case and the price for each package are set as 50 cents, 60 cents or 70 cents. In this case, it is assumed that 70 percent of the retail price is revenue to the manufacturer. As for the net margin, subtract both manufacturing costs and advertising costs with the revenue.

In this session, profit is calculated in two ways. In basic computation, using the mean value of the given sample and Table 3, monthly sales can be predicted and then the annual national sales can be calculated. Then the net margin for the first year can be calculated. In advanced computation, using Table 4, different sales of each month can be predicted. By adding them together and then using Table 3, annual national sales can then be calculated. Then the net margin can be predicted.

\subsubsection{Basic Computation}

Monthly sales(MS) can be assumed as the mean value of the sample:

$$
M S=\frac{\sum_{i=1}^{96} x_{i}}{n}=244 ;
$$

In this equation, $x i$ is the value of samples and $n$ is the sample size, which is 96 .

Annual national sales(ANS) can be calculated using the following equations:

$$
A N S=12 * M S \times N_{\text {stores }}=629520 ;
$$

In this equation, is the total number of stores in this nation, which is 215 .

Net margin(NM) can then be calculated as:

$$
\begin{aligned}
& M C=F C+A N S * V C=\$ 1.63 \text { million; } \\
& N M=A N S * 24 * P * 70 \%-M C-A C=
\end{aligned}
$$

$\$ 0.66$ million

$\mathrm{MC}$ is the manufacturing cost, $\mathrm{FC}$ is a fixed cost of $\$ 1$ million, VC is the variable cost, which is $\$ 1$ for each case, $\mathrm{AC}$ is the advertising cost, which is $\$ 3$ million.

According to the calculation above, the final net margin is $\$ 0.66$ million as is shown in formula(12).

\subsubsection{Advanced Computation}

Based on the parameter estimation, the Monthly Sales (MSi) can be predicted using the equation below:

$$
\begin{gathered}
M S_{i}=-110.398+27.207 * P 60+1.286 * P V 50+ \\
49.525 * A d+4.138 * V o l+38.835 * M_{i} ; \\
i=1,2, \ldots, 12 ;
\end{gathered}
$$

Annual national sales (ANS) can then be calculated as:

$$
A N S=\Sigma n_{\text {stores }} * \sum_{i=1}^{12} M S_{i} ;
$$

$\mathrm{n}_{\text {stores }}$ is the number of stores within a given range of store volume.

Net margin(NM) can then be calculated as:

$$
N M=A N S * 24 * P * 70 \%-M C-A C ;
$$

Using different combination of price and advertising method, different profit is shown in Table 5. Plan E has the most annual national sales and net margin as well. Therefore, considering both predicted annual national sales and the net margin, the final marketing mix is using the advertising of $\$ 3.5$ million and the price of 70 cents. The predicted net margin for the first year is $\$ 7$ million. 
Table 5. Marketing Mix

\begin{tabular}{|c|c|c|c|}
\hline Plans & Contents & ANS(Cases) & $\mathrm{NM}(\$$ million $)$ \\
\hline $\begin{array}{l}\text { Plan } \\
\text { A }\end{array}$ & $\begin{array}{l}\$ 3.5 \text { million } \\
\text { Advertising } \\
50 \text { cents per } \\
\text { package }\end{array}$ & 1267944 & 4.88 \\
\hline $\begin{array}{l}\text { Plan } \\
\text { B }\end{array}$ & $\begin{array}{l}\$ 3 \text { million } \\
\text { Advertising } \\
50 \text { cents per } \\
\text { package }\end{array}$ & 1140170 & 4.44 \\
\hline $\begin{array}{l}\text { Plan } \\
\text { C }\end{array}$ & $\begin{array}{l}\$ 3.5 \text { million } \\
\text { Advertising } \\
60 \text { cents per } \\
\text { package }\end{array}$ & 1154690 & 5.98 \\
\hline $\begin{array}{l}\text { Plan } \\
\text { D }\end{array}$ & $\begin{array}{l}\$ 3 \text { million } \\
\text { Advertising } \\
60 \text { cents per } \\
\text { package }\end{array}$ & 1026916 & 5.32 \\
\hline $\begin{array}{l}\text { Plan } \\
\text { E }\end{array}$ & $\begin{array}{l}\$ 3.5 \text { million } \\
\text { Advertising } \\
70 \text { cents per } \\
\text { package }\end{array}$ & 1084496 & 7.17 \\
\hline $\begin{array}{l}\text { Plan } \\
\text { F }\end{array}$ & $\begin{array}{l}\$ 3 \text { million } \\
\text { Advertising } \\
70 \text { cents per } \\
\text { package }\end{array}$ & 956721.9 & 6.29 \\
\hline
\end{tabular}

\subsection{Recommendations-4Ps}

regression equation modelling, and we will make some recommendations for K-Pack from two levels: First, the preliminary work is reflected in Product and Price, focusing on the summary of an optimal marketing Max given by the business analysis and linear regression modelling above; And the recommendations of future development will focus on the two aspects of Place and Promotion, which are not mentioned much in the previous article, so as to form a comprehensive discussion.

\subsubsection{Price}

The price of 70 Cents is a part of the best marketing mix.

Obviously, 70cents is the highest of the three prices, and the regression analysis shows that Buyers want the product at the price (When the highest price is 70cents the sales is still as high as 1081656), the quality of $\mathrm{K}$ pack and its image can support the price; in addition, there is little chance of a strong contender in the next two years, so we also know that competitors should not be able to enter the market easily; Fix cost is also determined by the number of products, so costs of producing the product in small volume should not cancel the advantage of higher prices.

Taken together, the market-skimming pricing strategy can be used for pricing suitably, which with high initial prices to "skim" revenue layers from the market.

It allows SMARTFOOD Company to put the K-Pack on the market at a price much higher than the cost, in order to make high profits in the short term, recoup the investment as soon as possible, and then gradually reduce the price. Apple used this strategy for most of its products when they first hit the market.

\subsubsection{Place}

From the box-plot in the regression analysis we can see that there is a slight difference in the placement of two sections of bakery and breakfast food: there will still be a slight increase in sales in Bakery. Therefore, it is recommended to place the K-Pack of Typical Candy Bar in the Bakery, after all its looks more like snacks rather than breakfast.

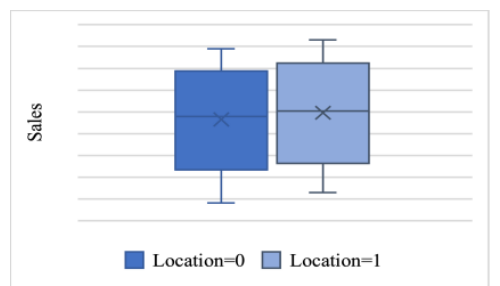

Figure 4. Boxplot of Sales and Location

\subsubsection{Product \& Some factors need attention for the product development manager}

The K-pack can be regarded as a shopping product for less frequent products of consumers. Therefore, Suggestions are given mainly from the following points:

a. Quality Control - K-pack is food, so we should pay more attention to strict control in quality inspection to ensure that there will be no mistakes in food safety of products. 
b. Diversified Packaging - Sweet-toothed people not always like the shape of typical candy bar, K-Pack can be made into a variety of shapes such as small cakes, in this way, may also improve the sales in the Breakfast Food section and broaden the types of K-pack stores. In terms of composition list and energy scale, it can be more colorful and make the characteristics of low carbon and health of K-PACK more prominent. And just as with the multi-generational family problem mentioned earlier, dynamics will inevitably affect how media and advertising messages resonate with Americans. Ultimately, it will influence who is the right target for the family version of food, children's entertainment, life insurance, and a range of products and services aimed at the family audience.

c. Warranty - Provide some quality assurance or add some after-sale service to increase the trust of potential customers who are on the fence about our products.

d. Brand strategy - protect unique features, create loyalty, establish barriers to entry.

\subsubsection{Promotion Strategy}

The Advertising cost $3.5 \mathrm{~m}$ of 70 Cents is a part of the best marketing mix. According to the regression model, advertising has a great effect on sales. Therefore, the forms of publicity should be diversified gradually on the basis of the existing single advertising model to find the best Promotion Mix.

Nine percent of American consumers now feel represented in ads, according to a Consumer Reports survey. For an industry that devotes so much time, money and talent to consumers, this is shockingly low and a sign of significant inefficiency. But why is there such a disconnect between the reality of American culture and the message being reflected by advertisers? The answer lies in understanding how the American consumer has changed over the past few years, and how the culture continues to evolve. From the rise of the multigenerational family, to the concept of intersectionality, to the changing nature of the "American Dream," many aspects of life are being transformed. Understanding this shift is critical for brands and media companies alike. And, as the mood of thousands of American consumers shows, marketers don't understand enough. And when searching for better diversity in advertising, a key nuance is to recognize what they really represent between different identity groups, and even between different segments of those groups.

Culture and visibility in advertising are important to different audiences. When it comes to the media, they want to see, who is more likely to be attracted to which of them, which illustrates the importance of applying cross-angles. For black Americans, for example, the main difference we see is the age difference. And older black
Americans are more eager to use ads to reflect their culture. Young black Americans, on the other hand, expressed a stronger eye concern -- celebrities, actors or web celebrities who looked like them.

This is an important difference, so a more sensitive and flexible approach can be formed to formulate multicultural marketing strategies for future K-pack diversified groups.

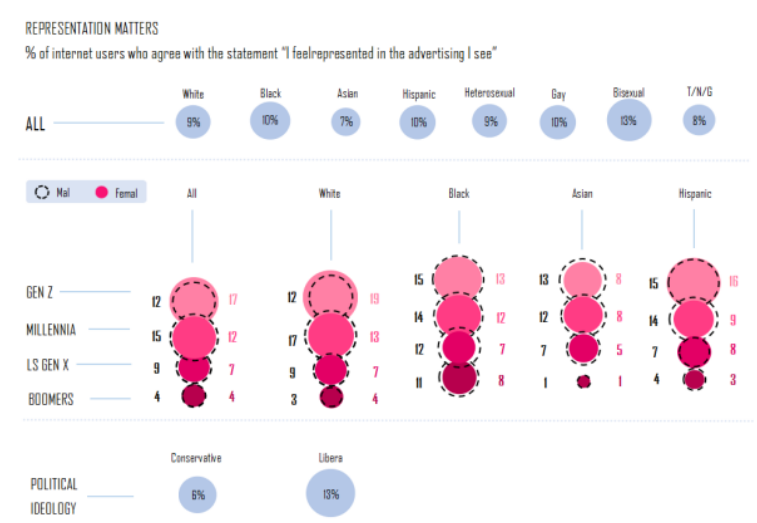

Figure 5. Percentage of Grandparents Living with Their Children or Other Family Members

\section{CONCLUSION}

This paper mainly uses PEST, Porter's Five Forces Model, SWOT analysis and other models combined with regression analysis to judge the trial sales results of SMARTFOOD Company's new low-food product, Kpack, and give some comprehensive suggestions for its future development. This provides a preliminary analysis framework and a reference development strategy for some enterprises with new products like K-Pack entering a new market mode.

In this paper, some business analysis models and multiple regression models are applied to decide the final marketing mix. Firstly, from the perspective of business analysis, this paper analyses the case using three different models, PEST analysis, Porter's five forces analysis and SWOT analysis. From PEST analysis, political, economic, social and technological factors are considered. From Porter's five forces analysis, some conclusions can be drawn from positions of different characters such as the rivalry, the suppliers, the buyers, the new entrants and the substitutes. From the SWOT analysis, strengths, weaknesses, opportunities and threats are analysed comprehensively. All the models show that the K-Packs have a promising future as well as some challenges and risks. Secondly, a multiple linear regression model is established to decide the marketing mix and its final net margin for the first year. There are five significant variables: Month, P60, PV50, Ad and Vol. Besides, in basic computation, without the help of the regression model, the predicted net margin is $\$ 0.66$ million while in advanced computation, using the regression results, the net margin is $\$ 7$ million. 
Considering both the results of the regression model and 4Ps, the final marketing mix is to apply the $\$ 3.5$ million advertising plan with the price of 70 cents for each package, setting in the bakery section.

Also, there are some shortcomings in our modelling: First, the current information will lead to inaccurate sales volume unpredictable due to the variation law; Second, although the independent variable city index is significant, it is omitted in the modelling, because there are only 4 cities in the known information data, so the maximum index is 4 . When the final net profit is forecast, there will definitely be more than 4 cities, so the index will not be equal to 4 . So it's also a bias due to the information we already know.

Therefore, since the market potential of new products is very large, it is not necessary for early entrants to focus on preventing competitors from entering, but it is more sensible to spend money on their own product development and expanding the market share of large products. It may be appropriate to encourage the entry of certain competitors by licensing or other means. Given the characteristics of an emerging stage, a firm can often benefit by having others desperately sell their industry's products and aid technology development.

\section{REFERENCES}

[1] Jia, S., Hou, C. , \& Wang, J. . (2017). Software aging analysis and prediction in a web server based on multiple linear regression algorithm. 2017 IEEE 9th International Conference on Communication Software and Networks (ICCSN). IEEE.

[2] Ul-Saufie, A. Z., Yahaya, A. S., Ramli, N. A., \& Hamid, H. A. (2012). Performance of multiple linear regression model for long-term pm10 concentration prediction based on gaseous and meteorological parameters. Journal of Applied Sciences, 12(14), 1488-1494.

[3] Hai-Hong, L. I., Gong, X. S., \& Tong, Z. (2010). Multiple linear regression prediction model applied to production forecast of rural household solid wastes. Southwest China Journal of Agricultural Sciences, 23(4), 1325-1328.

[4] Shan, Z., Zhao, D., \& Xia, Y. . (2013). Urban road traffic speed estimation for missing probe vehicle data based on multiple linear regression model. International IEEE Conference on Intelligent Transportation Systems. IEEE.

[5] Swangjang, K., \& Kornpiphat, P. (2021). Does ecotourism in a mangrove area at klong kone, thailand, conform to sustainable tourism? a case study using swot and dpsir. Environment Development and Sustainability(1).
[6] Rizzo, A., \& Kim, G. (2005). A swot analysis of the field of virtual reality rehabilitation and therapy. Presence, 14(2), 119-146.

[7] Yan, R., Yan, H., Yi-Sha, Y., \& Business, S. O. (2014). Study on the cultural tourism development of guanzhong-tianshui economic zone_-based on the swot-pest analysis. Journal of Xi'an University of Finance and Economics.

[8] Doherty, I., Steel, C., \& Parrish, D. (2012). The challenges and opportunities for professional societies in higher education in australasia: a pest analysis. Australasian Journal of Educational Technology, 28(1), 105-121.

[9] Alava, Ramona, \& Parraga. (2018). Pest analysis based on neutrosophic cognitive maps: a case study for food industry. Neutrosophic Sets and Systems, 21(1), 10-10.

[10] Bintong Yu, Rui Li, Xiangyu Gao, Wensheng Zhang, \& Zhigang Wang. (2018). The sales problems and purchasing influence factors of taiwan fruits in mainland china market_based on 475 questionnaires in fuzhou city. Food and Nutrition in China, 024(005), 42-45.

[11] Dodd, T. H., \& Gustafson, A. W. (1997). Product, environmental, and service attributes that influence consumer attitudes and purchases at wineries. Journal of Food Products Marketing, 4(3), 41-59.

[12] Noh, E., Lee, S. K., \& Lee, B. . (2017). Analyzing influence factors of foodservice sales by rebuilding spatial data: Focusing on the conversion of aggregation units of heterogeneous spatial data. 